\title{
Prevention of Rh-haemolytic Disease: Results of the Liverpool "Low-risk" Clinical Trial
}

\author{
J. C. WOODROW, C. A. CLARKE, R. B. MCCONNELL, SHONA H. TOWERS, W. T. A. DONOHOE
}

British Medical fournal, 1971, 2, 610-612

\section{Summary}

A clinical trial is reported in which $\mathrm{Rh}$-negative primiparae, just delivered of an Rh-positive ABO-compatible infant and in whom fetal cell counts after delivery suggested less than $0.2 \mathrm{ml}$ of circulating fetal blood, were treated with about $200 \mu \mathrm{g}$ of anti-D gammaglobulin. Three $(0.36 \%)$ out of 844 women thus treated developed anti-D in the subsequent six months; this is $10 \%$ of the incidence in untreated controls. Three $(1.8 \%)$ out of 171 treated mothers had anti-D at the end of the second Rh-positive pregnancy, and this is $18 \%$ of the incidence in controls.

Possible reasons for the occasional failure of the treatment are discussed and the results of this trial are compared with those of a previous trial in which $1,000 \mu \mathrm{g}$ or more of anti-D was given to a different group of mothers. The combined results of the two trials lead to the conclusion that the passive administration of anti-D gammaglobulin after delivery affords in this population of $\mathbf{R h}$-negative women a $95 \%$ protection rate in the postdelivery period and an $89 \%$ protection rate by the end of the subsequent pregnancy.

\section{Introduction}

In our report of a clinical trial to test the effectiveness of about $1,000 \mu \mathrm{g}$ of anti-D gammaglobulin in preventing $\mathrm{Rh}$ immunization of Rh-negative primiparae (Combined Study, 1966) it was noted that a further trial had been initiated in Liverpool. The plan of this second one was to treat mothers showing less than an estimated $0.2 \mathrm{ml}$ of $\mathrm{Rh}$-positive fetal blood in their circulation after delivery with about $200 \mu \mathrm{g}$ of anti-D gammaglobulin. The results of this trial are presented here and some implications discussed.

\section{Design of trial}

In general the design of the trial was similar to that described for the $1,000-\mu \mathrm{g}$ trial. $\mathrm{Rh}$-negative primiparae were ascertained in five maternity units immediately after the delivery of $\mathrm{ABO}$ compatible Rh-positive infants. Maternal blood samples were tested by the Kleihauer-Betke technique (Kleihauer et al., 1957), the scoring system previously described being used (Combined Study, 1966). Mothers were selected for the trial in whom a fetal cell score of 0-4 was found, suggesting less than

Nuffield Unit of Medical Genetics, Department of Medicine, University of Liverpool, Liverpool L69 3BX

J. C. WOODROW, M.D., F.R.C.P., Senior Lecturer in Medicine

C. A. CLARKE, M.D., F.R.C.P., F.R.S., Professor of Medicine and Director of the Nuffield Unit of Medical Genetics

R. B. McCONNELL, M.D., F.R.C.P., Research Fellow

w. T. A. DONOHOE, A.I.M.L.T., C̈hief Technician

Chester Royal Infirmary, Chester

SHONA H. TOWERS, M.D., M.R.C.o.G., Consultant Obstetrician and Gynaecologist
$0.2 \mathrm{ml}$ of circulating fetal blood. In the absence of treatment the incidence of anti-D six months after delivery in this group was about $6 \%$. Alternate cases were treated by administering intramuscularly $1 \mathrm{ml}$ of a gammaglobulin solution containing $200 \mu \mathrm{g}$ of anti-D (N. C. Hughes-Jones, personal communication, 1967). (At this time mothers showing $0 \cdot 2 \mathrm{ml}$ or more of fetal blood were being treated with 1,000 $\mu \mathrm{g}$ of anti-D (Combined Study, 1971).) The aim was to administer the anti-D by intramuscular injection within 36 hours of delivery, but in some instances this could not be done and delays of up to three to five days occasionally occurred. The untreated cases served as controls.

\section{Tests for antibodies}

Control and treated mothers were visited at home about six months after delivery and samples of venous blood obtained. Various methods were used in order to ascertain the occurrence of subsequent pregnancies, and further samples of blood were obtained immediately after this second delivery. In many instances blood was also taken at about 35 weeks of this second pregnancy.

The sera were tested for antibodies in saline and albumin and by antiglobulin and papain methods.

\section{Results}

The results of testing six months after delivery are shown in Table I. Thirteen $(3.6 \%)$ out of 362 control mothers had developed anti-D at this time. None of 353 treated mothers showed antibodies.

The results of testing 255 of these women for antibodies at the end of the second Rh-positive pregnancy are given in Table II. Included are cases in which the second baby was either $\mathrm{ABO}$ compatible or incompatible. Thirteen out of 127 control mothers had anti-D, four having developed it previously within six months of the first delivery. Thus nine

TABLE I-Results of Tests for Antibodies Six Months after Delivery

\begin{tabular}{ccc|c|c|c}
\hline & & & No. & $\begin{array}{c}\text { Not } \\
\text { Immunized }\end{array}$ & Immunized \\
\hline Controls & $\ldots$ & $\ldots$ & 362 & 349 & $13(3 \cdot 6 \%)$ \\
Treated & $\ldots$ & $\ldots$ & 353 & 353 & 0 \\
\hline Total $\ldots$ & $\ldots$ & $\ldots$ & 715 & 702 & 13 \\
\hline
\end{tabular}

TABLE II-Results of Tests for Antibodies at End of Second Rh-positive Pregnancies

\begin{tabular}{|c|c|c|c|c|c|}
\hline & & & No. & $\begin{array}{c}\text { Not } \\
\text { Immunized }\end{array}$ & Immunized \\
\hline $\begin{array}{l}\text { Controls } \\
\text { Treated }\end{array}$ & .. & . & $\begin{array}{l}127 \\
128\end{array}$ & $\begin{array}{l}114 \\
125\end{array}$ & $\begin{array}{c}13\left(4^{*}\right)(10 \cdot 2 \%) \\
3(2 \cdot 3 \%)\end{array}$ \\
\hline Total & .. & $\ldots$ & 255 & 239 & 16 \\
\hline
\end{tabular}

Number of mothers who had developed antibodies after the first pregnancy. They are included in the larger number. 
controls developed antibodies during this second pregnancy as against 3 out of 128 in the treated group. The following are the details of these failures of prophylaxis.

Case 1.-A group O Rh-negative mother was treated about 24 hours after the delivery of a group $O$ Rh-positive infant, a fetal cell score of 1 being found (a score of 5 implies approximately $0 \cdot 2$ $\mathrm{ml}$ of circulating fetal blood). No antibodies were found on testing six months later, and she became pregnant again. A routine test at 34 weeks of this second pregnancy showed no antibodies, but at delivery her serum showed anti-D $+C$ by saline and antiglobulin techniques. The infant was group $\mathrm{O} R \mathrm{R}$-positive, direct Coombs positive, but was only very mildly affected.

Case 2.-A group B Rh-negative mother was treated about 24 hours after delivery of a group $\mathrm{O}$ Rh-positive infant, the fetal cell score being 1 . Tests for antibodies were negative six months later, and at this time she was already three months pregnant again. Routine antenatal testing at 20 weeks of pregnancy was negative, but at 34 weeks anti-D was detected by saline, albumin, and antiglobulin techniques. She was induced at 38 weeks, and a group B Rh-positive infant was delivered showing a positive direct Coombs test. The haemoglobin at birth was $115 \%$ but fell to $60 \%$ subsequently. The child did well without transfusion.

Case 3.-A group $\mathrm{O} \mathrm{Rh}$-negative mother showed no circulating fetal cells after delivery of a group $\mathrm{O}$ Rh-positive infant and was treated with anti-D about 24 hours after delivery. Tests were made for antibodies and were negative six months later. She became pregnant again a year after this. A routine test at 30 weeks of pregnancy showed no antibodies, but anti-D in saline and albumin was present at delivery. A group $O$ Rh-positive infant was delivered at home and appeared healthy. No clinical observations suggesting the presence of neonatal anaemia or jaundice were made but a direct Coombs test was not carried out.

\section{FURTHER TREATED MOTHERS}

When the controlled trial ended it was decided that all mothers at risk should be treated and we have data on 491 further women selected in the same way and who were given $200 \mu \mathrm{g}$ of anti-D after delivery. Three were found to have anti-D six months later, demonstrable by saline, albumin, and antiglobulin methods. The fetal cell scores in these women after delivery were 0,1 , and 3 respectively. It may be relevant that in two mothers the anti-D was not given until the third and fifth day after delivery. The total incidence of anti-D six months after delivery in all treated mothers is, therefore, 3 out of $\mathbf{8 4 4}$ $(0.36 \%)$. This is exactly $10 \%$ of the incidence in the controls and indicates a $90 \%$ protection rate.

Some time after the controlled trial ended we decided to treat, with $200 \mu \mathrm{g}$, women with a fetal cell score of 5 to 25that is, 0.2 to $1.0 \mathrm{ml}$ of circulating fetal blood. So far we have followed for six months 48 women in this series, none of whom has developed antibodies.

Forty-three mothers treated after the end of the controlled trial have had second $\mathrm{Rh}$-positive pregnancies and none showed anti-D at the end of this pregnancy. Thus out of a total of 171 treated mothers $3(1.8 \%)$ had anti-D at the end of the subsequent pregnancy. This is about $18 \%$ of the incidence of antibodies after a second pregnancy in the control women. In other words the degree of protection achieved was $82 \%$.

\section{MOTHERS WITH ANTIBODIES AT DELIVERY}

In order to avoid delay in the administration of anti-D it was not routine practice to test for antibodies the pretreatment maternal blood samples before the administration of the anti-D gammaglobulin. It therefore happened that seven mothers who received anti-D gammaglobulin were found on later testing to have anti-D in their pretreatment sera. All showed anti-D in the samples taken six months after delivery. In five instances both baseline and six-month samples showed strong activity by albumin and Coombs techniques. In two mothers the baseline samples showed activity only by an enzyme method and their six-month samples showed no significant change in the behaviour of these antibodies.

\section{Discussion}

The results of this trial show the efficiency of the preventive treatment, and there are some interesting comparisons to be made with a first and larger dose trial carried out in Liverpool and other centres (Combined Study, 1971). The trial described here differs from the first one in two respects. Firstly, the dose of anti-D is of the order of $200 \mu \mathrm{g}$ while that in the first trial was $1,000 \mu \mathrm{g}$ or more. Present evidence suggests, however, that for most treated women in the two trials this difference in dosage was of no significance. Secondly, selection of mothers for this present trial was based on zero or very low count of fetal cells after delivery, while a substantial count of fetal cells was a requisite for the inclusion of a mother in the first trial. A superficial consideration of the matter might lead one to expect that the failure rate would be lower in the present trial since the amount of $\mathrm{Rh}$-positive fetal blood in the maternal circulation at the time of treatment was smaller. In fact, there is a suggestion of a somewhat higher incidence of failure in the present trial as judged both by antibody tests six months after delivery (if mothers treated after the end of the controlled trial are included the rate of protection is $90 \%$ ) and by tests at the end of the subsequent pregnancy (protection rate $82 \%$ ). These figures can be compared with those for the first trial-that is, $97 \%$ and $93 \%$ respectively (Combined Study, 1971).

The question must be posed of why failures of therapy occurred in this present trial when the amount of anti-D given might have been expected easily to protect against the volumes of $\mathrm{Rh}$-positive blood present in the maternal circulation at the time of treatment. Indeed, in two instances no fetal cells were counted in maternal blood samples after delivery. The most likely explanation is that transplacental haemorrhage, possibly of substantial size, had occurred some time before delivery and that a primary immune response with total or partial clearance of the fetal cells had occurred by the time of delivery. In other words, when the anti-D was given the primary immune response had already begun, and the anti-D was too late to prevent the further development of the immune response. That $\mathrm{Rh}-$ positive red cells can be cleared at a stage in the immune response when there is no demonstrable antibody has been shown by Mollison et al (1969). They injected $34 \mathrm{Rh}$-negative male volunteers with $\mathrm{Rh}$-positive red cells, giving some anti-D as well, and challenged them later with ${ }^{51} \mathrm{Cr} \mathrm{Rh}-$ positive red cells. By serological testing only two of the 13 subjects who initially received red cells alone (no anti-D) developed antibody, but five other controls showed subnormal cell survival at 7 to 10 days after they had been challenged, indicating that priming had occurred. Woodrow et al (1969) carried out similar studies in volunteers from which again it was evident that rapid clearance of Rh-positive cells took place after challenge even though there was no detectable antibody present in volunteers who made conventional antibodies later.

In contrast to the above situation, the presence of a more substantial volume of fetal blood at delivery in the first trial would favour protection in that the immune response is less likely to have begun in these mothers, and in many cases the transplacental haemorrhage occurred either very late in pregnancy or during labour.

Because of the risk of priming during a first pregnancy Canadian workers have been, and are now, treating women during the third trimester (Zipursky and Israels, 1967; Buchanan et al., 1969; Bowman, 1970). We await the results of the extensive Manitoba trial with interest. This approach might be expected to prevent most failures since priming during the latter part of pregnancy seems to be a commoner cause of the failure of postpartum treatment than is the occurrence of unusually large transplacental haemorrhages. 


\section{GENERAL ASSESSMENT OF Rh PROPHYLAXIS}

If one assumes that the difference in dosage of anti-D used in the present trial and that used in the first one (Combined Study, 1971) is irrelevant, it is of interest to combine the data from the two trials in order to make an overall assessment of the degree of success achieved. Women coming within the category of this present trial are a little over four times as common in our population as those in the first trial category. If this is taken into account, the overall incidence of antibodies developing in the six months after treatment can be estimated to be $0.4 \%$. This is $4.9 \%$ of the expected $8.2 \%$ incidence of antibodies six months after first ABO-compatible pregnancies (Woodrow, 1970). This represents, therefore, a $95 \%$ protection rate at this time.

The cumulative incidence of antibodies at the end of the second pregnancies subsequent to treatment is estimated to be $1.9 \%$ overall. This is $11 \%$ of the expected $17.3 \%$ incidence of anti-D at this time. The protection rate at this stage is thus $89 \%$.

Two points are worth making in relation to this latter figure. Firstly, in four instances of failure which have occurred in the two trials the anti-D has not appeared until relatively late in the second pregnancy. Experience in Liverpool suggests that $0.8 \%$ of Rh-negative women develop antibodies during the first $\mathrm{Rh}$ positive pregnancy, and it seems quite likely that in many instances this represents a primary response. It may well be that a similar event occasionally occurs in the $\mathrm{Rh}$-positive pregnancy following treatment, and in these circumstances it cannot be expected that the anti-D administered after the previous pregnancy will prevent the appearance of antibodies at this time.

Secondly, the crude incidences of antibodies may not quite tell the whole story. It is possible that some women who without treatment would develop anti-D in the months after the first pregnancy are prevented from doing so by the administration of anti-D gammaglobulin, but because the immune response is not totally suppressed they start the second pregnancy in a primed state and are thus at risk of developing antibodies later during this second pregnancy. Though such a case would be counted as a failure, the treatment may in fact have been of considerable benefit to the second Rh-positive infant which, instead of being exposed throughout the period of pregnancy to maternal anti- $\mathrm{D}$, is exposed to antibody only during the latter part of the pregnancy, the antibodies, in addition, probably being of lower affinity.

\section{PROBLEM OF IMMUNIZED MOTHERS}

No definite effect of the administration of $200 \mu \mathrm{g}$ of anti-D was seen in the seven mothers who had antibody in the pre- treatment samples. Though the fact that the two mothers showing papain-active anti-D (negative in saline, albumin, and by Coombs test) before treatment still showed the same type of antibody six months later, we can draw no firm conclusions because another mother showing similar antibody at delivery was given $1,000 \mu \mathrm{g}$ of anti-D, and in spite of this a strong albumin and Coombs-positive anti-D was found six months later.

In general it is not to be expected that mothers who have demonstrable antibody in their blood can be helped by the administration of anti-D gammaglobulin. An attempt to prevent the further development of the immune response in mothers with very weak anti-D at delivery has been made by Godel et al. (1968). These weak antibodies could sometimes be detected only by using ficin or protease treated -D-/-D- cells, and in five out of nine untreated mothers the antibody could not be found six months later. Thus the fact that only 1 of their 13 treated mothers showing this type of antibody at delivery still had a positive test six months later is difficult to assess. However, as the authors argue, the immune response in the mothers may have been only in the form of $\operatorname{IgM}$ antibody at the time anti-D was given and the further development of the response with the appearance of IgG anti-D may have been prevented. Further results are awaited with interest, and it remains to be seen whether these observations have an important practical bearing.

This trial would not have been possible without the help of numerous individuals and these are detailed in the report of a previous clinical trial (see Combined Study, 1971).

\section{References}

Bowman, J. M. (1970). British fournal of Haematology, 19, 653.

Buchanan, D. I., Bell, R. E., Beck, R. P., and Taylor, W. C. (1969). Lancet, $2,288$.

Combined Study from Centres in England and Baltimore (1966). British Medical fournal, 2, 907.

Combined Study from Centres in England and Baltimore (1971). British Medical fournal, 2, 607.

Godel, J. C., Buchanan, D. I., Jarosch, Jean M., and McHugh, Maureen (1968). British Medical fournal, 4, 479.

Kleihauer, E., Braun, H., and Betke, K. (1957). Klinische Wochenschrift, 35, 637 .

Mollison, P. L., Hughes-Jones, N. C., Lindsay, M., and Wessely, J. (1969).

Vox Sanguinis, 16421.

Woodrow, J. C. (1970). Series Haematologica, 3, No. 3.

Woodrow, J. C., Finn, R., and Krevans, J. R. (1969). Vox Sanguinis, 17, 349.

Zipursky, A., and Israels, L. G. (1967). Canadian Medical Association Fournal, 97, 1245. 